844 Table 14.3 , column 1 , row 3 , change " $v_{D}$ " to "v $D$ ". Left-hand column, lines 2 and 3, change "the Wyckoff letter (column 1), the multiplicity (column 2)" to "the Wyckoff letter (column 2), the multiplicity (column 1)".

850 Left-hand column, line 17, change "Auslöchungen" to "Auslöschungen".

851 Right-hand column, line -30 , change "(Table 14.3, 845 " to "(Table 14.3), 845".

851 Right-hand column, line -21 , change "Laue class symmetry)" to "Laue class and symmetry".

852 Right-hand column, line -20 , change "Priority rule, 50,806 " to "Priority rule, 52, 806".

Acta Cryst. (1987). A43, 838-839

\section{Prices of Acta Crystallographica and Journal of Applied Crystallography}

The Executive Committee of the International Union of Crystallography is pleased that it has not been necessary to increase the subscription rates and the prices of back numbers for Acta Crystallographica and Journal of Applied Crystallography as from 1 January 1988. This is the fifth consecutive year for which prices have remained constant.

\section{Acta Crystallographica}

The following rates will apply for Volumes A44, B44 and C44 (1988). All subscription rates are fixed in Danish kroner. The US dollar equivalents are no longer given because of rapid fluctuations in exchange rates.

Complete volumes, regular price per volume

Sections A, B \& C (combined subscription)

Dkr 5250

Section A only

Section B only

Dkr 1275

Dkr 1275

Section C only

Dkr 3000

Complete volumes, reduced price for individuals

Sections A, B \& C

(combined subscription)

Section A only

Section B only

Section C only

Dkr 1450

Dkr 350

Dkr 350

Dkr 850

All subscribers in the USA and Canada should add to the above subscription rates the additional charges for airfreighting as mentioned below.

The reduced-rate subscriptions are ordinarily only available to members of recognized scientific societies, and applications must be accompanied by a written undertaking that the journal is for the personal use of the subscriber and will not be made available to libraries, institutions, etc. These conditions also apply to persons wishing to order back numbers at the reduced rates.

Single parts

The price for single parts of any Section of Volume 44 (1988) is Dkr 320.

\section{Journal of Applied Crystallography}

The following rates will apply for Volume 21 (1988). All subscription rates are fixed in Danish kroner. The US dollar equivalents are no longer given because of rapid fluctuations in exchange rates.

Complete volumes, regular price per volume

Dkr 1275

Complete volumes, reduced price for individuals

Dkr 400

All subscribers in the USA and Canada should add to the above subscription rates the additional charge for airfreighting as mentioned below.

The same conditions apply to reduced-rate subscriptions as in the case of Acta Crystallographica (see above).

Single parts

The price for single parts of Volume 21 (1988) is Dkr 320.

\section{Airfreighting of copies to the USA and Canada}

Deliveries of Acta Crystallographica and Journal of Applied Crystallography to the USA and Canada in 1988 will continue to be by air freight to New York and thence by second class mail. The use of this service is obligatory for all subscribers in those countries. The charges in Danish kroner are as given below.

\section{Acta Crystallographica}

Sections A, B \& C

(combined subscription) Add Dkr 380

Section A only

Section B only

Section C only

Add Dkr 90

Add Dkr 90

Journal of Applied Crystallography Add Dkr 70

\section{Prices of back numbers}

All these prices are fixed in Danish kroner. The US dollar equivalents are no longer given because of rapid fluctuations in exchange rates. 


\section{Acta Crystallographica}

Complete volumes, regular price per volume

Vols. 1-23

Combined Vols. 24-38

Dkr 1275

Combined Vols. 39-43

Dkr 4600

Vols. A24-A43

Vols. B24-B38

Vols. B39-B43

Vols. C39-C43

Complete volumes, reduced price for individuals

Vols. 1-23

Combined Vols. 24-38

Combined Vols. 39-43

Vols. A24-A43

Vols. B24-B38

Vols. B39-B43

Vols. C39-C43

\section{Single parts}

Single parts of Volumes 1-23 are not available. The price of single parts of any Section of other Volumes is Dkr 320 .

Cumulative Indexes, regular price

Vols. 11-23 (1958-1967)

Vols. 24-28 (1968-1972)

Vols. 29-38 (1973-1982)

Dkr 120

Dkr 120

Dkr 150
Cumulative Indexes, reduced price for individuals

Vols. 11-23 (1958-1967)

Vols. 24-28 (1968-1972)

Vols. 29-38 (1973-1982)

Dkr 60

Dkr 60

Dkr 75

A few copies of the cumulative index for Volumes 1-10

(1948-1957) are also available, free of charge.

Journal of Applied Crystallography

Complete volumes, regular price per volume

Vols. 1-20

Dkr 1275

Complete volumes, reduced price for individuals

Vols. 1-20

Dkr 400

Single parts

The price for single parts of any volume is $\mathrm{Dkr} 320$.

\section{Orders}

Orders for Acta Crystallographica and Journal of Applied Crystallography may be addressed to Munksgaard International Publishers Ltd, 35 Nørre Søgade, DK-1370 Copenhagen K, Denmark. Orders from subscribers in North America may alternatively be placed through Polycrystal Book Service, PO Box 3439, Dayton, OH 45401, USA.

\section{Book Reviews}

Works intended for notice in this column should be sent direct to the Book-Review Editor (R. O. Gould, Department of Chemistry, University of Edinburgh, West Mains Road, Edinburgh EH9 3JJ, Scotland). As far as practicable books will be reviewed in a country different from that of publication.

Acta Cryst. (1987). A43, 839-840

Symmetry: unifying human understanding. (Vol. 10 of Modern applied mathematics and computer science, Series editor E. Y. Rodin.) Edited by I. HargitTaI. Pp. xvi + 1045. Oxford: Pergamon Press, 1986. Price US $\$ 115.00$.

This is a coffee-table book, not a textbook at all - for it gives no single, coherent, developed account of its subject.

But what a coffee-table book! A serious and a massive one. The coffee table itself will have to be strongly made, and many hundreds of cups of coffee will be poured before the contents of this book are fully absorbed, such is the size and such the volume, detail and variety of the contents of this production.

It is a collection of 65 mostly quite disparate essays, each on some symmetry-related topic, contributed by a galaxy of distinguished authors from 18 different countries. Each of these essays is a small gem in its own right; they average about 16 pages in length (about 10000 words, since the print is small); they are in excellent English and are usually complete with a business-like list of references. There are very many fascinating illustrations all through the book, some ten or so in colour. It is a book that is hard to put down once one has lifted it up. Only in one case (Zvilna, on trihedrons) are there some infelicities.

The sheer range of subject areas is striking. Predictably, quite a number of the essays are on symmetry in the graphic arts (about nine); but there are also articles on symmetry in ornaments, dance, music, mathematics, fractals, even literature, as well as biology, physics and chemistry. Symmetry in various aspects of chemistry scores ten essays (of course, the editor is a chemist himself) which include symmetry considerations in reactions, bonding, isomerism and the Periodic Table. Readers of Acta Cryst. will want to know how crystallography fares in this compilation. Indeed, some six or seven essays are explicitly related to crystallography. Of these, the one I find most interesting and readable (although the English here is occasionally less than perfect) is Vainshtein's, on biological molecules; Senechal's essay is also both interesting and thoughtful, ending by posing the unsolved problem of the origin of twinned crystals, after a fine survey of crystal morphology; 